Dicle University Journal of Engineering (DUJE)

Araştırma Makalesi / Research Article

\title{
Geosentetik Donatı Sayısı ve Konumunun Farklı Boyutlu Yol Numuneleri Üzerine Etkisinin İncelenmesi
}

\author{
oInvestigation of Effect of Geosynthetic Reinforcement and Placement on Road \\ Samples with Different Size \\ Elif Çiçek ${ }^{1 *}$ \\ 1* Hacettepe Üniversitesi, İnşaat Mühendisliği Bölümü, Ankara, elif.cicek@ hacettepe.edu.tr
}

\begin{tabular}{l} 
MAKALE BİLGILERİ \\
\hline Makale geçmişi: \\
Geliş: 30 Aralık 2019 \\
Düzeltme: 9 Mayıs 2020 \\
Kabul: 17 Mayıs 2020 \\
\hline Anahtar kelimeler: \\
Yol, geosentetik, boyut, donatı \\
sayıs1, sonlu elemanlar yöntemi
\end{tabular}

\begin{abstract}
ÖZET
Bu çalışmada, sonlu elemanlar yöntemi kullanılarak oluşturulan modeller için geosentetik donatının etkileri incelenmiștir. Plaxis 2D programı ile farklı model boyutlarında seçilen örnekler üzerinde yapılan analiz sonuçları değerlendirilmiştir. $5 \mathrm{~cm}$ ile $960 \mathrm{~cm}$ arasında alınan farklı model genişlikleri için yol temel tabakası modellenerek gerilme deformasyon davranışı ve oturma miktarları değerlendirilmiştir. Modellerin kırılma davranışları ile modeller içine konulan tek ve çoklu donatı tabakası (1, 2 ve 3) kullanılma durumları için de değerlendirmeler yapılmıştır. Tek donatının numune içinde farklı bölgelere konulmasının etkileri de karşılaştırılmıştır. En iyi performansın üç adet donatı kullanılması durumunda görüldüğü belirtilebilmektedir. Donatısız durumda model boyutu pek etkili olmasa da donatılı modeller için numune ölçülerinin etkili olduğu görülmüştür. Ayrıca, oturma ve numunelerin kırılma modellerinde donatının etkili olduğu görülmüştür.
\end{abstract}

Doi: 10.24012/dumf.667928

\begin{tabular}{|c|c|}
\hline ARTICLE INFO & ABSTRACT \\
\hline Article history: & \multirow{6}{*}{$\begin{array}{l}\text { In this study, the effects of the geosynthetic reinforcement for the models created by finite element method have } \\
\text { been investigated. The results of the analysis on samples selected with different model sizes were evaluated with } \\
\text { Plaxis } 2 \mathrm{D} \text { program. For different model widths taken between } 5 \mathrm{~cm} \text { and } 960 \mathrm{~cm} \text {, the base layer of road was } \\
\text { modeled and the stress deformation behavior and settlement amounts were evaluated. The failure behavior of the } \\
\text { models and the single and multiple reinforcement layers }(1,2 \text { and } 3) \text { used in the models were also evaluated. The } \\
\text { effects of placing the single reinforcement in different regions in the sample were also compared. It can be stated } \\
\text { that the best performance is seen in case of three reinforcements. Although the model size was not very effective } \\
\text { in the case of the reinforcement, it was seen that the sample sizes were effective for the reinforced models. In } \\
\text { addition, it was found that the reinforcement was effective in settlement and failure patterns the samples. }\end{array}$} \\
\hline Received: 30 December 2019 & \\
\hline Revised: 9 May & \\
\hline Accepted: 17 May 2020 & \\
\hline Keywords: & \\
\hline $\begin{array}{l}\text { Road, geosynthetic, scale, } \\
\text { number of reinforcement, fini }\end{array}$ & \\
\hline
\end{tabular}

* Sorumlu yazar / Correspondence

Elif ÇiÇEK

$\bowtie$ elif.cicek@hacettepe.edu.tr 


\section{Giriș}

Bilindiği üzere yolların iyileştirilmesi için geosentetiklerin kullanılması son zamanlarda daha da popüler bir duruma gelmiştir $[1,2]$. Geosentetiklerin kara yolu stabilitesi ve ömrünü arttırdı ̆̆ 1 bilinse dahi farklı donatı parametrelerinin etkileri henüz kesinlik kazanmamıştır. Diğer bir deyişle donatının yol modeli içinde hangi bölgeye yerleştirilmesi gerektiği ve donatı sayısının yolun taşıma kapasitesi veya gerilme-deformasyon davranışına nasıl etki edeceği ile ilgili kesinleşmiş ve kurallaşmış tasarım konfigürasyonu veya hesaplamalar bulunmamaktadır. Genellikle konulan donatının etkisinin, yol modelindeki konumuna ciddi ölçüde bağlı olduğu ve yol tabakalarının incelendiği boyutlar önemli olduğu bilinmektedir. Ancak literatürde yapılan birçok çalışmada kullanılan modeller farklı büyüklüktedir. Örneğin, birçok çalışmada küçük ölçekli numunelerde yol dolgu tabakası içine geosentetik donatı konulmuş ve donatı etkisi laboratuvarda araştırılmıştır [3, 4]. Fakat Elton ve Patawaran [5] gibi bazı araştırmacılar ise 76 cm genişliğindeki daha büyük ölçekli laboratuvar deneyleri ile geosentetik donatı etkisini incelemişlerdir. Hem nümerik hem de deneysel araştırmalarda oluşturulacak modelin boyutları büyük önem taşısa da fakat henüz tam anlamıyla açıklığa kavuşmamıştır. Bilindiği üzere, büyük boyutlu inşaat yapıları laboratuvarda küçük numunelerle temsil edilmektedir. Arazide ise küçük bir bölümde yapılan araştırmalarda bulunan sonuçlar yolun tamamı için uygulanmaya çalışılmaktadır. Diğer bir deyişle, trafik yükleri altındaki geosentetik ile donatılandırılmış bir yol için incelenmesi gereken ölçek tam anlamıyla bilinmediğinden ötürü, laboratuvar testlerinden elde edilen sonuçlar tek başına baz alınamamaktadır $[6,7]$. Ayrica, Nguyen vd. [4] laboratuvarda yapılan deneylerin ölçek etkisinden etkilenebileceğini ve yolların tasarımında önemli bir yeri olabileceğini vurgulamışlardır. Yine birçok çalışmada karayolu statik trafik yükü ile benzer şekilde modellenen temel plakası ile yapılan bazı çalışmalarda da ölçek etkisinin öneminden bahsedilmiştir $[8,9,10] . \mathrm{Bu}$ nedenle bu çalışmada farklı büyüklüklerdeki modeller incelenmiştir.

Yollar ile ilgili literatürdeki birçok çalışma laboratuvarda, arazide veya sonlu elemanlar metodu kullanan bir program vasitasiyla yapılmıştır. Tam ölçekli yani gerçek kesitli deneyler malzeme temini ve işçilik açısından hem uzun zaman alır hem de maliyetleri yüksektir. Bu nedenle, sonlu elemanlar yöntemi ile analiz yapan bir programın kullanımı, bir yap1 elemanının büyük yükler altında tepkisini tahmin etmek için yaygın bir şekilde kullanılmaktadır [11-14]. Bu çalışmada da sonlu elemanlar hesabı yapan iki boyutlu Plaxis programı kullanılmıştır. Donatının tek veya çok sayıda kullanılmasının etkilerinin de önemli olabileceği bilinmektedir. Böylece bu çalışmada farklı konum ve sayıda kullanılma durumları da incelenerek değişik numune boyutlarındaki etkileri değerlendirilmiştir. Farklı parametrelerin numune oturmasına etkileri karşılaştırılmıştır.

\section{Yöntem ve Malzeme}

Çalışmada, sonlu elemanlar yöntemini kullanarak analiz yapan Plaxis 2D 2018 programı kullanılmıștır. Bir karayolunun temel tabakasının zemin örneğini taşıyan yol dolgusunun modellendiği numune analizleri yapılmıştır. Literatürde karşılaşılan analizlerde genellikle tekerlek izine $550 \mathrm{kPa}$ değerinde basınç yükü tatbik edildiği görülmüștür $[15,16]$. Gerek statik gerekse de dinamik analizlerde genellikle bu değer baz alınarak çalıșmalar yürütülmüştür. $\mathrm{Bu}$ nedenle bu çalışmada da bu değer göz önüne alınarak statik olarak yayılı yük şeklinde düşey yükleme yapılmıștır. Model genişlikleri (B) $5 \mathrm{~cm}$, $15 \mathrm{~cm}, 30 \mathrm{~cm}, 60 \mathrm{~cm} 120 \mathrm{~cm}, 480 \mathrm{~cm}$ ve $960 \mathrm{~cm}$ ve yükseklikleri genişliğin iki katı alınmıştır. İlk analizlerde numuneler $550 \mathrm{kPa}$ basinc1 taşıyamadıklarından ötürü numunelerin dik durabilmesi için genellikle üç eksenli deneylerde de çoğunlukla uygulanan hücre basıncı olarak ifade edilen sabit bir yanal basınç uygulama değeri $100 \mathrm{kPa}$ olarak alınarak yol dolgu numuneleri için analizler yapılmıştır [17]. Literatürden seçilerek, zemin malzemesinin birim hacim ağırlığ1, sürtünme açısı, Young modülü ve Poisson oranı değerleri sirasıyla $21 \mathrm{kN} / \mathrm{m}^{3}, 45^{\circ}$, $5000 \mathrm{kPa}$ ve 0.35 alınmıştır [18]. Zemin modeli çoğunlukla literatür çalışmalarında da kullanılan Mohr Coulomb modeli ile tanımlanmıştır. 
Geosentetik malzemenin eksenel rijitlik değeri $400 \mathrm{kN} / \mathrm{m}$ değerlerinde alınmıștır. Numune ă̆ (mesh) aralıkları sıkı olarak dikkate alınmıștır. Sonlu elemanlarda, örneğin $\mathrm{B}=15 \mathrm{~cm}$ genişlikli numune modeli için eleman sayısı 324, düğüm noktasi say1s1 2705, ortalama eleman boyutu $8,33 \times 10^{-3} \mathrm{~m}$ olarak alınmıştır. Literatür incelenerek [19, 20, 21] geometrik şekli ve sınır koşulları tanımlanan modellerde altta tamamen deformasyon sınırlandırılmış, üstte ise yükleme ve deformasyon tanımlanmıştır. Numune aralarına geosentetik malzemeler ise farklı donatı sayılarında tanımlanmıştır. Şekil 1'de görüldüğü üzere geosentetik donatı malzemesinin modellerin içerisine yerleştirilme düzenleri belirtilmektedir. Şekil 1.a'da donatısız yani geosentetik olmadan sadece model analizini, Şekil 1.b donatı modelin tam ortasına bir adet, Şekil 1.c ve Şekil 1.d donatının $\mathrm{H} / 4$ ve $3 \mathrm{H} / 4$ oranlarında modelin içine konması temsil edilmektedir. Şekil 1.e ve Şekil 1.f'de ise çoklu donatı tabakası sayılı yani 2 ve 3 adet donatının konulması durumlarını göstermektedir. Çalışmada yol numuneleri için donatıların bu farklı konumlara yerleştirilmesi durumundaki değişimler incelenmiş ve sonuçlar birbirleri ile karşılaştırılmıştır.

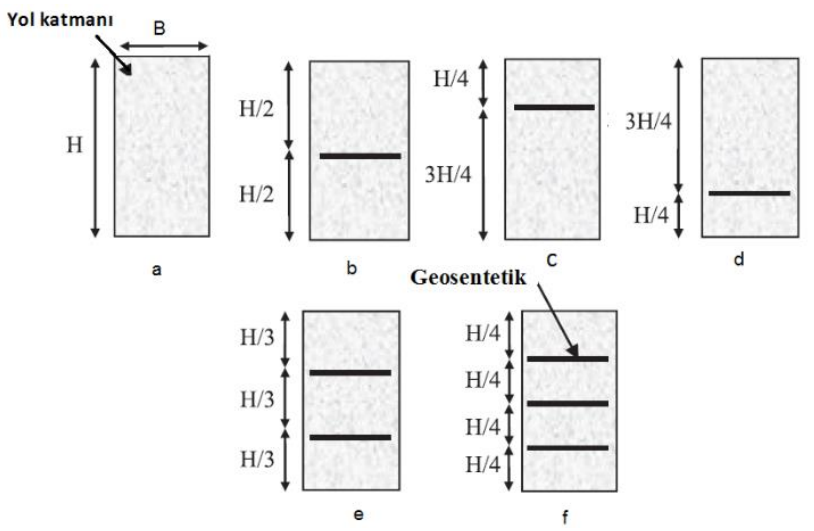

Şekil 1. Donatı yerleşim planları; a) Donatısiz, b) Numune ortasinda tek adet, c) Numune H/4 oranindaki mesafede tek adet, d) Numune 3H/4 oranindaki mesafede tek adet; e) İki adet donatılı model, $f$. Üç adet donatılı model.

Figure 1. Reinforcement placement parameters a) Unreinforced, b)one layered in the middle, $c$ ) one layered in the H/4 ratio, d) one layered in $3 \mathrm{H} / 4$ ratio, e) Two layered reinforcements, f) Three layered reinforcements model.

\section{Sonlu Elemanlar Analizi Sonuçları}

Sonlu elemanlar programı kullanılarak yapılan analiz sonuçları donatısız ve donatılı olmak üzere iki farklı kategoride belirtilmiştir. Ayrıca, donatılı modeller tek ve çok donatı tabakalı olmak üzere farklı bölümlerde incelenmiştir. Sayısal analizlerden elde edilen tüm sonuçlar birlikte değerlendirilerek genel bir değerlendirme yapılmıştır.

\section{Donatısız yol dolgu malzemesi örnekleri için yapılan analizler:}

Beklendiği üzere, iyileştirilmemiş yol zemin örnekleri için numune boyutunun değişmesi, gerilme-deformasyon davranışında mühendislik açısından büyük ve önemli oranlarda değişimlerin olmadığını göstermiştir (Şekil 2a). Fakat 480 ve $960 \mathrm{~cm}$ genişlikli çok büyük boyutlu örneklerde yükün elastik davranış durumunda bile daha fazla taşıyamadığı ve diğer örneklere nazaran daha küçük yüklemelerde göçme meydana geldiği gözlenmiştir. Böylece, numuneler arasındaki boyut fark1 çok büyüdügünde (örneğin 100 kat) gerilmedeformasyon davranışında aynı sonuçlar alınmasının güçleştiğgi belirlenmiştir. Analizler sonucunda farklı numune boyutları için numune genişliği ile yatay ve düşey oturma değişimleri ile ilgili Şekil 3'te elde edilen grafikler değerlendirildiğinde sonuçlar arasında bir bağıntı olduğu görülmüştür. Numuneler genellikle orta bölgeye yakın bir kısımda Coulomb teorisine uyumlu bir şekilde, Maher ve Gray [22]'in bahsettiği gibi orta bölgeye yakın kısımdan kırıldığı gözlenmiştir (Şekil 2b).

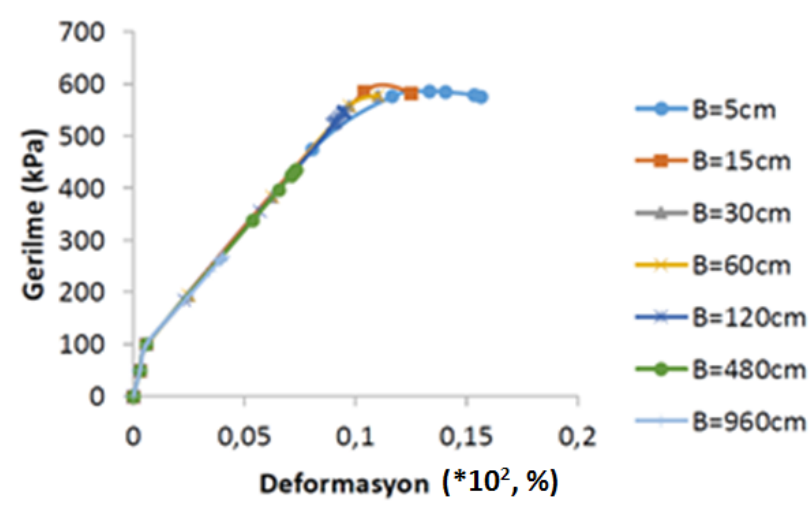




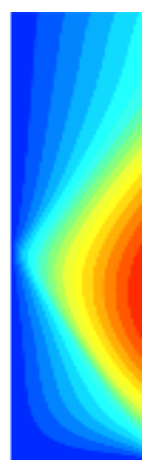

b

Şekil 2. Donatısız durum, a) Gerilmedeformasyon, b) Kırılma davranışı

Figure 2. Unreinforced model, a) Stressstrain, b) Failure behavior

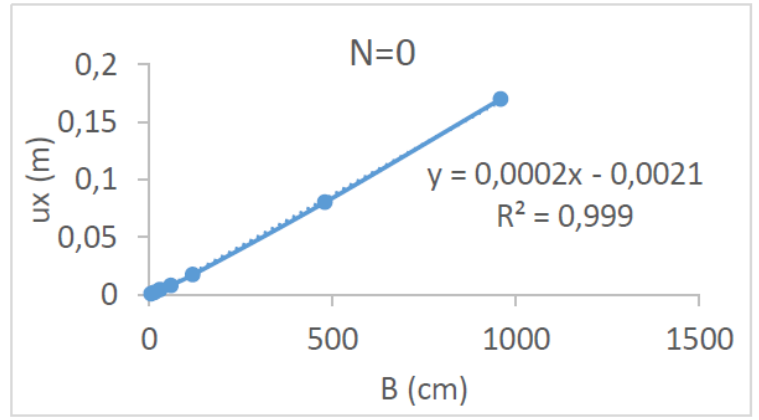

a

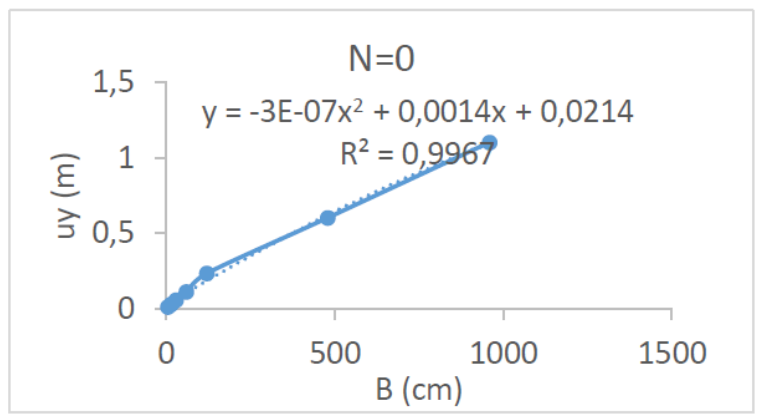

b

Şekil 3. Donatısız durum, a) yanal, b) düşey oturmalar

Figure 3. Unreinforced model, a) horizontal, b) vertical settlements

\section{Donatılı yol dolgu malzemesi örnekleri için yapılan analizler:}

a. Tek donatı tabakası kullanılma durumundaki analizler:
Donatının model içerisine tek adet kullanıldığ analizler üç farklı bölümde incelenmiștir. Donatı model içine ortada $(\mathrm{H} / 2), \mathrm{H} / 4$ ve $3 \mathrm{H} / 4$ derinliklerinde konulduğundaki analiz sonuçları incelenmiştir. Diğer bir deyişle donatılar, Şekil 1.b, Şekil 1.c ve Şekil 1.d'deki gibi yerleştirilmişlerdir. Analiz sonuçları incelendiğinde ise donatının farklı konumlara yerleştirilmesinin sonuçları değiştirdiği gözlenmiştir. Üst tabakada, dolgu içine H/4 yüksekliğine bir adet geosentetik donatı konarak oluşturulan analizlerde, gerilme-deformasyon eğrisinin maksimum gerilme değerleri Şekil 4.a'da verilmiştir. Gerilme deformasyon eğrisinin eğimi aynı kalsa da farklı boyutlarda oluşabilecek maksimum gerilme miktarının değiştiği belirlenmiştir. Donatı yukarıda iken yol altındaki dolgu zemin daha yumuşak davranmış ve kırılma alt bölgede meydana gelmiştir (Şekil 4b). Oturma miktarının ise boyut arttıkça büyüdüğü belirlenmiştir (Şekil 5).

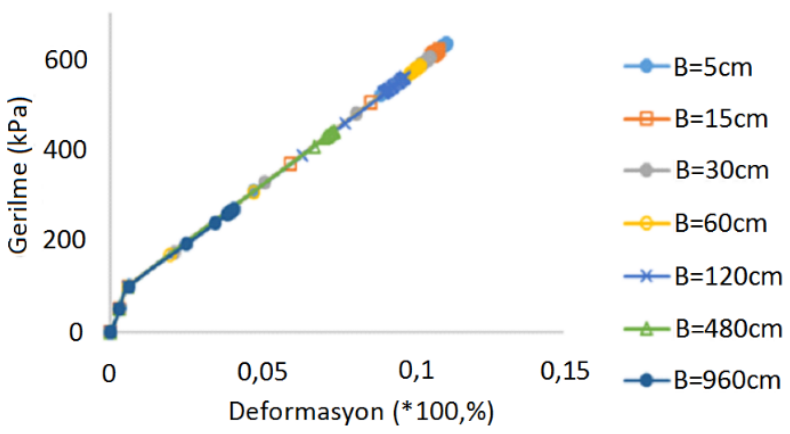

$\mathrm{a}$

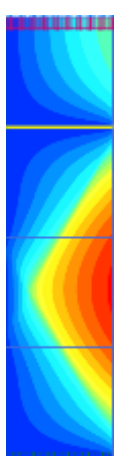

b

Şekil 4. Donatı H/4'te, a) gerilmedeformasyon, b) kırılma davranışı

Figure 4. Reinforcement in $H / 4$, a) stressstrain, $b$ )failure behavior 


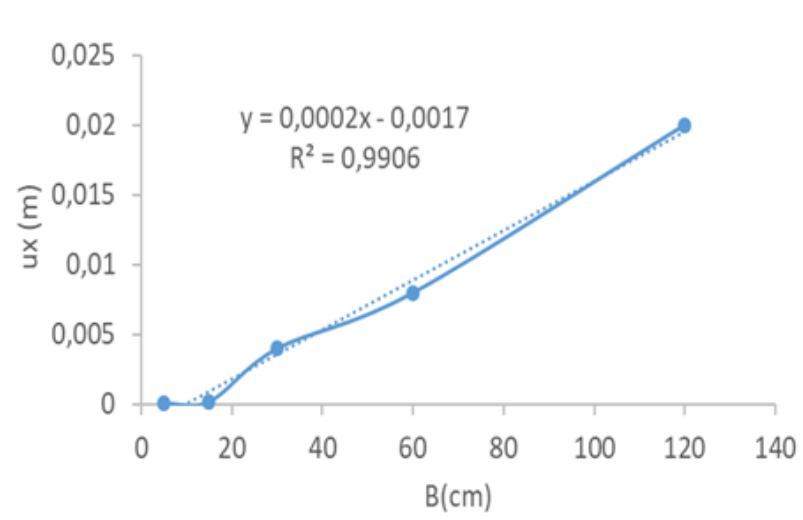

a

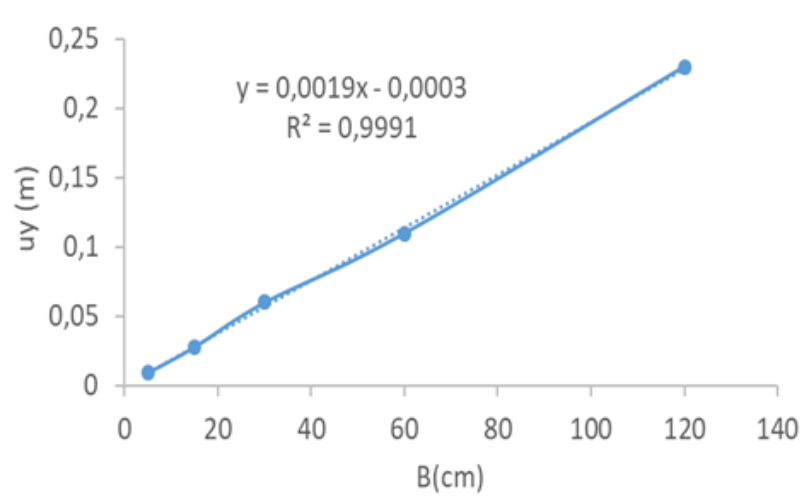

b

Şekil 5. Donatı H/4'te, a) yatay, b) düşey oturmalar

Figure5. Reinforcement in H/4, a) horizontal, b) vertical settlements

Geosentetik, yol numunesinin alt bölümüne yani $3 \mathrm{H} / 4$ mesafesine konulduğunda ise deformasyon değerlerinin plastik bölgede farklılık gösterdiği ve oturma miktarlarının da değiştiği gözlenmiştir (Şekil 6). Özellikle maksimum gerilme oranlarında değişimler oluşabileceği, numunelerin genellikle kendi malzeme özelliklerinden ötürü kırıldığı ve donatının oturmadan ziyade kırılma davranışına daha fazla etki ettiği belirlenmiştir. Böylece, numune donatının üst bölgesinde kırılma göstermiştir (Şekil 7). $480 \mathrm{~cm}$ ve $960 \mathrm{~cm}$ gibi çok büyük örnekler ise daha küçük gerilmelerde kırılmıştır. Bilindiği üzere geosentetik donatıların daha aktif çalışmaları için bir miktar deformasyona ihtiyaç vardır, fakat bu durumda zemin kendi içinde göçebilmekte ve henüz geosentetik çalışmadan kırılmalar olabilmektedir [23]. Bu nedenle geosentetiğin kullanıldığı gerçek projelerde daha dikkatli olunması gerektiği belirtilebilmektedir.
Ayrıca, Şekil 7'den de görüldüğü üzere deformasyon değişimi benzer olsa da oturmalar arasında fark vardır.

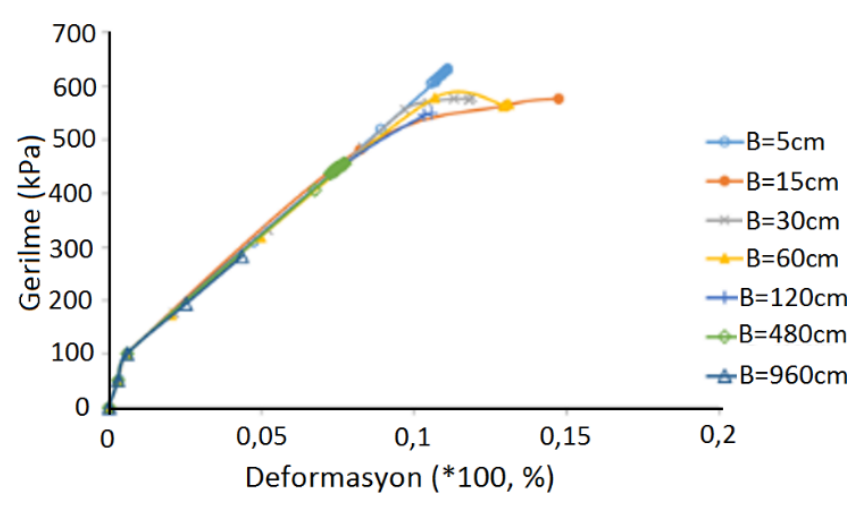

a

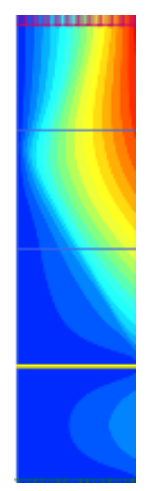

b

Şekil 6. Donatı 3H/4'te, a) gerilmedeformasyon, b) kırılma davranışı

Figure 6. Reinforcement in 3H/4, a) stressstrain, b) failure behavior

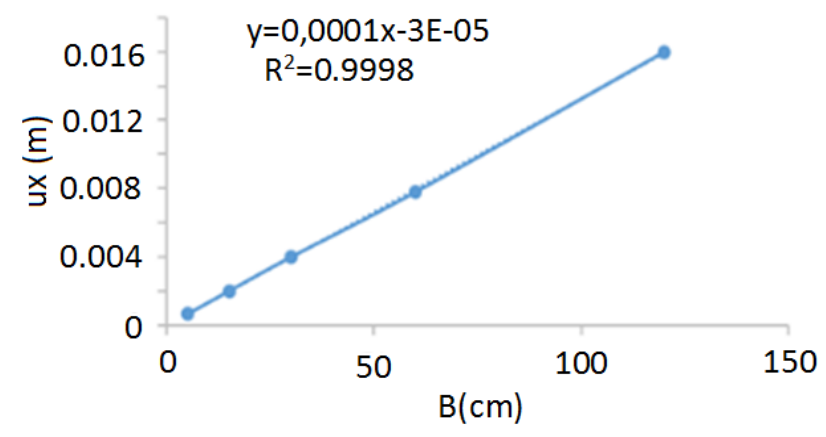

a 


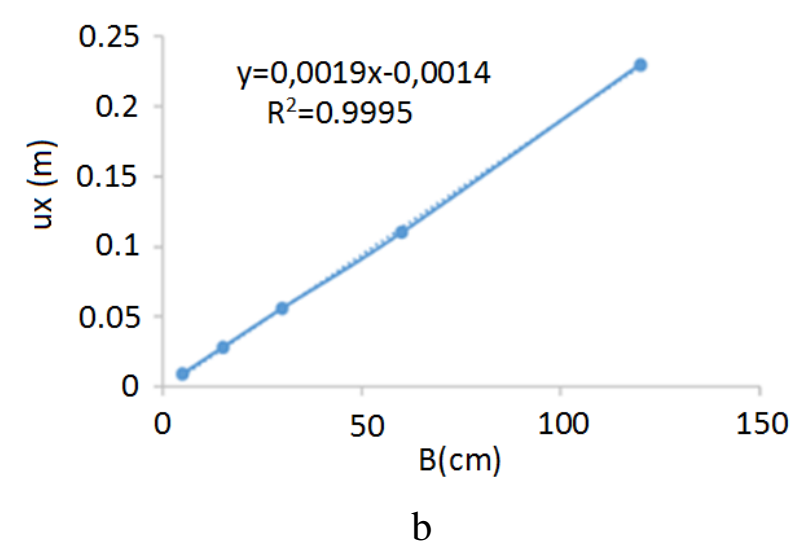

Şekil 7. Donatı 3H/4'te, a) yatay, b) düşey oturmalar

Figure7. Reinforcement in 3H/4, a) horizontal, $b$ ) vertical settlements

Farklı boyutlardaki modellerin tam ortasina geosentetik donatı yerleştirilmesi durumundaki analizlerinden elde edilen hesaplamalar Şekil 8 'deki gibidir. Yüklemenin sonlarında oturma değerlerinde büyük farklılıklar oluşabildiği gözlenmiştir. Sonuç olarak, $5 \mathrm{~cm}-120 \mathrm{~cm}$ genişlikli numune modellerinde tek donatı kullanıldığında $550 \mathrm{kPa}$ değerindeki tekerlek yükü taşınabilirken, $480 \mathrm{~cm}$ ve daha büyük modellerde tek donatılı durumda da göçme meydana gelmiştir. Diğer bir deyişle tanımlanan malzeme özellikleri nedeniyle yük taşınamamış ve tek donatı konması da mevcut durumu iyileştirememiştir. Gerilme-deformasyon eğrisinin elastik bölgesinde pek bir değişim olmazken plastik bölgede küçük boyutlu numunelerin daha fazla yük alabildiği, fakat numune boyutu arttıkça daha az gerilmeye maruz kaldığı gözlenmiştir. Modellerin yaptıkları oturmalar lineer davranışa yakın bir durum sergilemekte ve boyut arttıç̧a daha fazla oturmaların olduğunu söylenebilmektedir (Şekil 9). Model kırılıncaya kadar yüklendiğinde ise Şekil 8b'den de görüldüğü üzere tek donatılı numuneler donatının yukarı kısmından kırılma göstermektedir. Yani donatı numuneyi iki parçaya bölmüss ve donatı altındaki kısım daha az hasar görmüştür. Bu durum yol inşaatında önemli bir uygulama sağlayabileceğini göstermiştir. Çünkü zayıf zeminler üzerine inşa edilen yollar için alttaki zemin kazılarak yenisi konulduğunda ekonomik olarak daha fazla maddi ihtiyaca gerek duyulmaktadır. Fakat donatı kullanılması alttaki zeminin etkisinin azaltılmasını ve daha az dolgu kullanılma firsatını mümkün k1labileceğini göstermiştir.

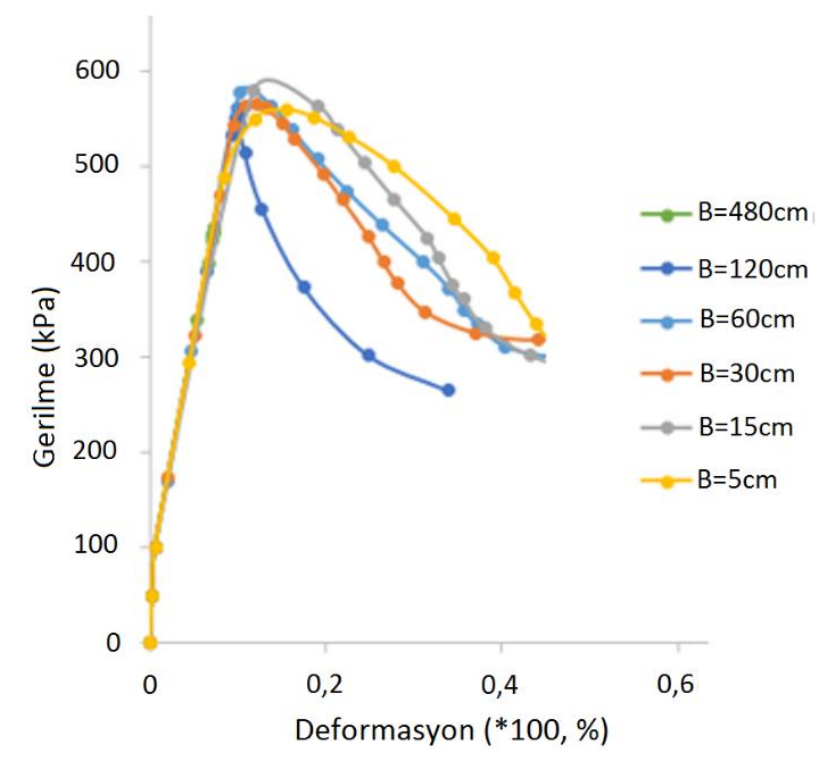

a

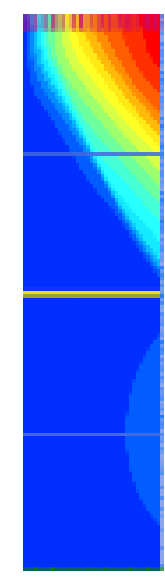

b

Şekil 8. Donatı numunenin ortasinda, a) gerilme-deformasyon, b) kırılma davranışı

Figure 8. Reinforcement in the middle, a) stress-strain, b) failure behavior

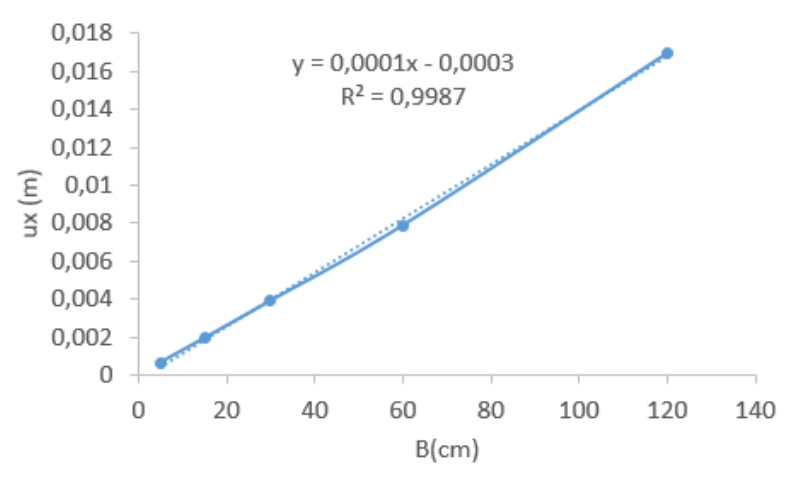

a 


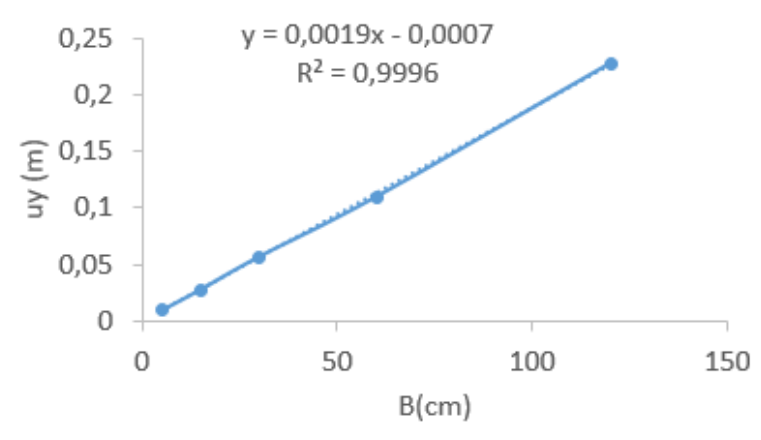

b

Şekil 9. Donatı numunenin ortasında, a) yatay, b) düşey oturmalar

Figure 9. Reinforcement in the middle, a) horizontal, b)vertical settlements

b. Çoklu donatı tabakası kullanılma durumundaki analizler:

$\mathrm{Bu}$ analiz grubunda donatı sayısının çoklu olma durumu (2 ve 3 adet) için analizler yürütülmüştür. Şekil 10 ve 11 incelendiğinde ölçek büyüdükçe donatının etkisi ve yanal deformasyonların aynı yükte değiştiği gözlenmiştir. İki donatılı modellerde plastik deformasyon durumunda model boyutunun etkisinin daha fazla olduğu görülmüştür. Donatı sayısı üç olduğunda ise modelin alabileceği maksimum gerilme miktarında değişimlerin olduğu belirlenmiştir. Yine $480 \mathrm{~cm}$ gibi çok büyük boyutlarda ise donatılı olsa da modeller yükü güvenle taşıyamamıştır. Böylece, numune ile gerçek boyut arasındaki farkın çok arttığı ve gerçek koşulların modellenmesinde daha dikkatli olunması gerekliliği önem kazanmıştır. Şekil 12 ve Şekil 13 ise oturma davranışları ile ilgili bilgi vermektedir.

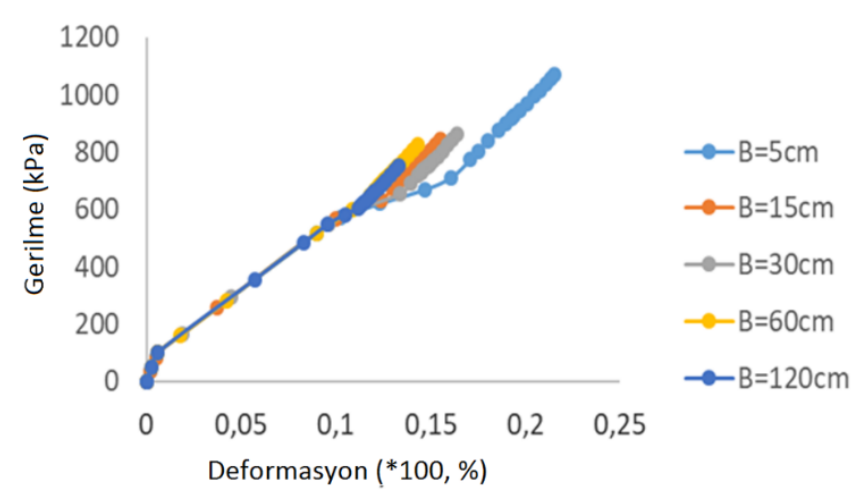

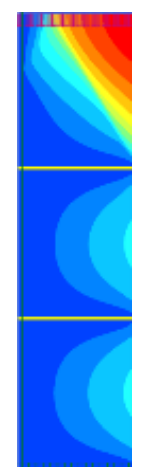

b

Şekil 10. İki donatıl model, a) gerilmedeformasyon, b) kırılma davranışı

Figure 10. Two reinforced model, a) stressstrain, b) failure behavior

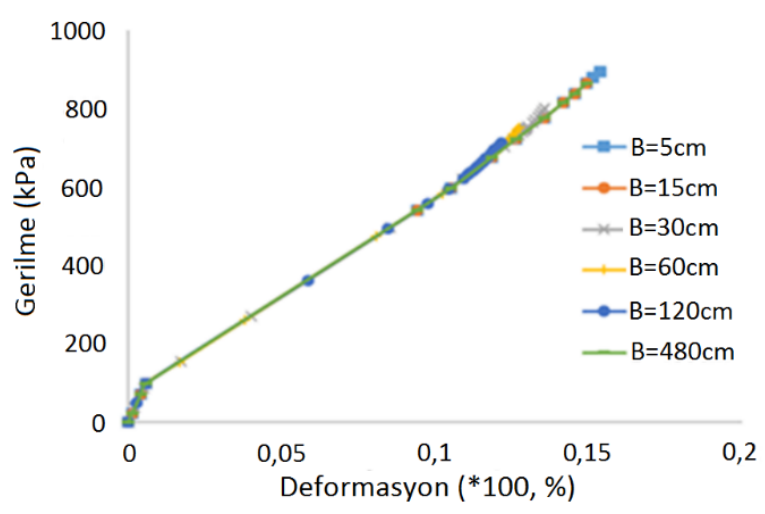

a

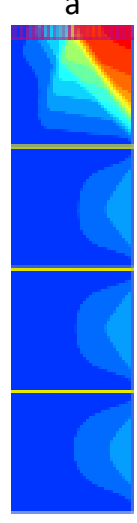

b

Şekil 11. Ü̧̧ donatılı model, a) gerilmedeformasyon, b) kırılma davranışı

Figure 11. Three reinforced model, a) stressstrain, b) failure behavior 

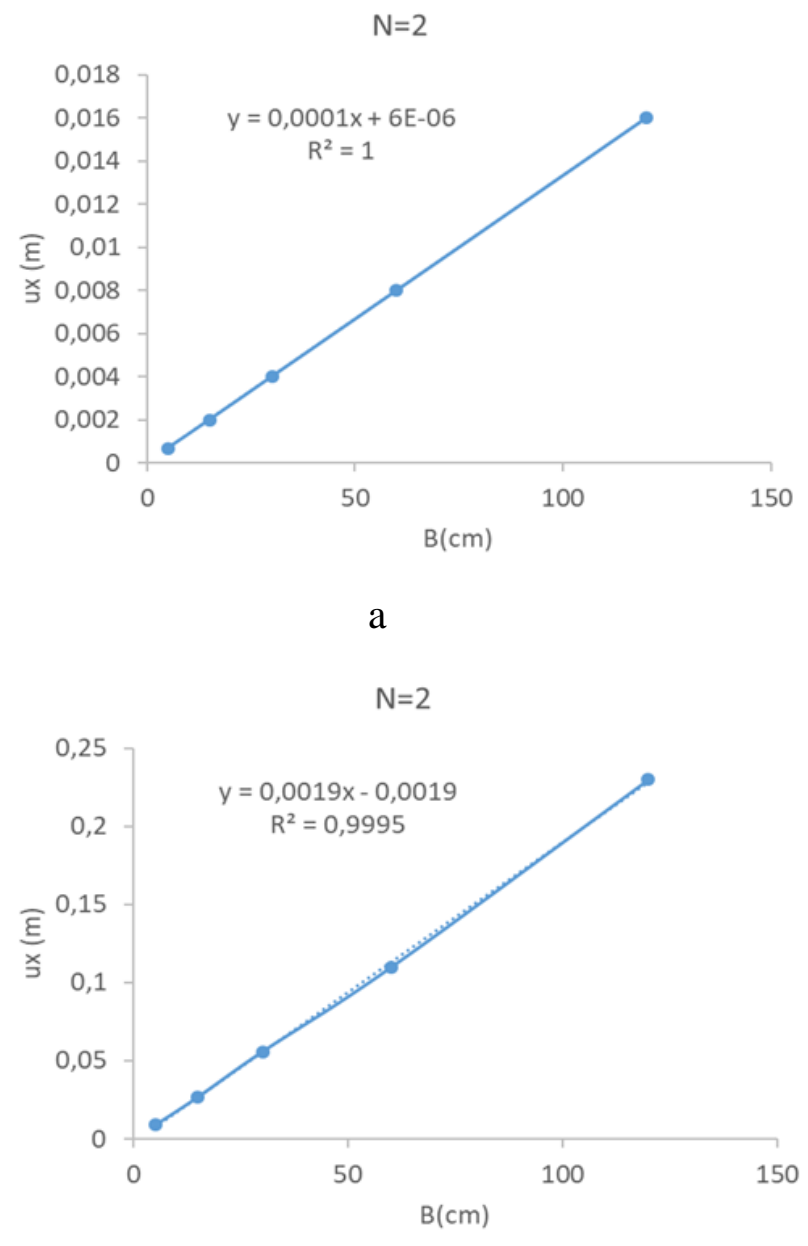

b

Şekil 12. İki donatılı model, a) yatay, b) düşey oturmalar

Figure 12. Two reinforced model, a) horizontal, b)vertical settlements

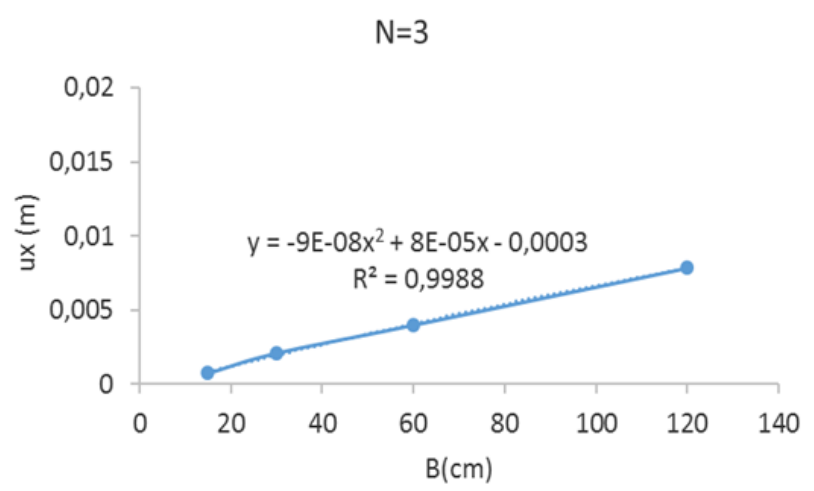

a

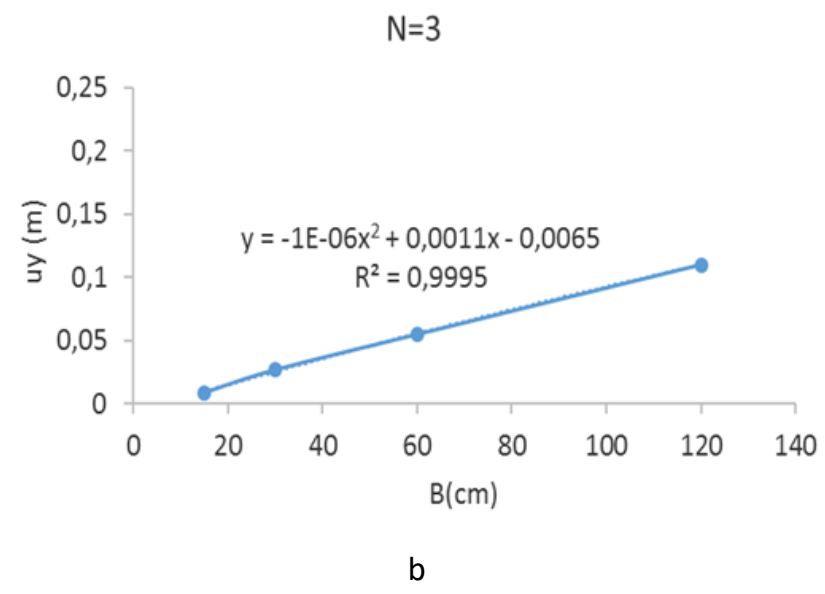

Şekil 13. Üç donatılı model, a) yatay, b) düşey oturmalar

Figure 13. Three reinforced model, a) horizontal, b)vertical settlements

Donatısız ve donatılı sistemlerde farklı koşullara göre $550 \mathrm{kPa}$ tekerlek yükü olarak düşünülen düşey yük için yatay ve düşey oturma davranışlarını özetleyen formüller Tablo 1'deki gibi verilmiştir. Yapılan çalışma ile donatının özellikle plastik bölgede daha etkin olduğu belirlenmiştir. Bilindiği üzere geosentetik donatıların daha etkin çalışmaları için bir miktar oturma olmasına ihtiyaç duyulduğuna dair bilgiler literatürde yayınlanan çalışmalarda [23, $24,25,26]$ da görülmüştür ve bu çalışma ile de plastik bölgenin önemi belirtilebilmektedir. Farklı donatılı modeller değerlendirildiğinde ise örneğin $\mathrm{B}=15 \mathrm{~cm}$ için gerilme-deformasyon eğrisi Şekil 14'teki gibidir. Donatı sayısı arttıkça özellikle elastik davranış sonrası model daha farklı davranış sergilediği gözlenmiştir. Beklendiği üzere donatı sayısı arttıkça daha büyük yükler taşınabilmiştir, fakat her donatılı durumun etkisi birbirinden farklı olmuştur. Bilindiği üzere karayollarının uzun süreli davranış1 önemlidir, fakat yolun fazla deformasyon alması yol güvenliği ve trafik akışı için pek istenen bir durum değildir. Bu nedenle yol yapım sırasında ön yüklemeler ile donatıların çalışır duruma getirilmesi ve yol inşası tamamlandiktan sonra daha güvenli ve daha az deformasyona müsaade eden güçlü yol davranışı gözlenmesi amaçlanabilmektedir. 
Tablo 1. $550 \mathrm{kPa}$ yük altında oturma davranışı

Table 1. Settlement behavior under $550 \mathrm{kPa}$ loading value

\begin{tabular}{|c|c|c|c|}
\hline \multirow{2}{*}{\multicolumn{2}{|c|}{ Donatı say1sı (N) }} & \multicolumn{2}{|c|}{ Oturmalar } \\
\hline & & $\mathrm{u}_{\mathrm{x}}(\mathrm{m})$ & $\mathrm{u}_{\mathrm{y}}(\mathrm{m})$ \\
\hline \multicolumn{2}{|c|}{0} & $0.0002 \mathrm{~B}-0.0021$ & $0.3 \mathrm{E}-07 \mathrm{~B}^{2}+0.0014 \mathrm{~B}+0.0214$ \\
\hline \multirow{3}{*}{1} & Üstte (H/4) & $0.0002 \mathrm{~B}-0.0017$ & $0.0019 \mathrm{~B}-0.0003$ \\
\hline & Altta (4H/4) & $0.0001 \mathrm{~B}-0.00003$ & $0.0019 \mathrm{~B}-0.0014$ \\
\hline & Ortada $(\mathrm{H} / 2)$ & $0.0001 B-0.0003$ & $0.0019 \mathrm{~B}-0.0007$ \\
\hline \multicolumn{2}{|r|}{2} & $0.0001 \mathrm{~B}+0.000006$ & $0.0019 \mathrm{~B}-0.0019$ \\
\hline \multicolumn{2}{|r|}{3} & $-9 \mathrm{E}-08 \mathrm{~B}^{2}+8 \mathrm{E} 05 \mathrm{~B}-0.003$ & $-1 \mathrm{E}-06 \mathrm{~B}^{2}+0.0011 \mathrm{~B}-0.0065$ \\
\hline
\end{tabular}

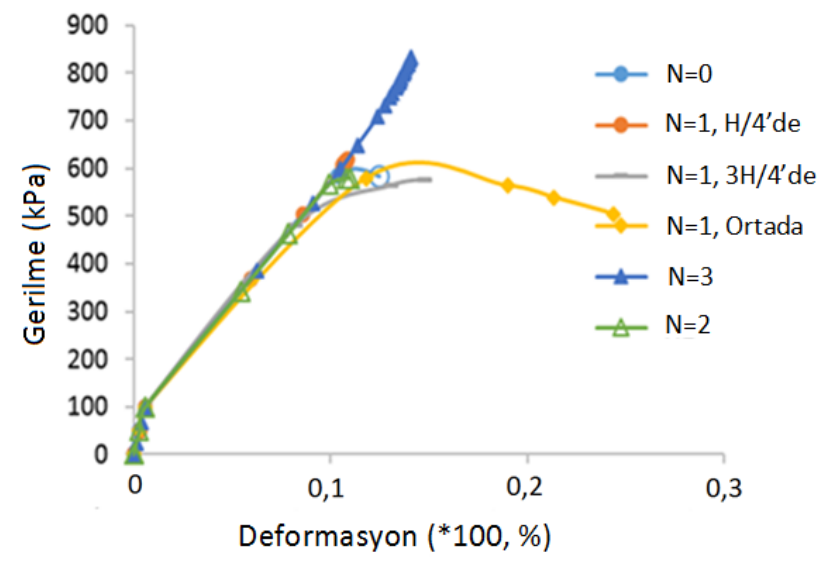

Şekil 14. $B=15 \mathrm{~cm}$ için farklı donatı parametrelerinin karşıllaştırılması

Figure 14. Comparison of different reinforcement parameters for $B=15 \mathrm{~cm}$

Bilindiği üzere gerçek yol projelerinde sahada hızlı çözüm bulmak gerekebilecektir. Farklı donatı durumlarının değerlendirilmesi önemlidir ve alınan numuneler ile kararlar verilmektedir. $\mathrm{Bu}$ çalışma ile görülmüştür ki numunelerin boyutları önemli olabilmekle beraber donatının konumu da sadece taşıma kapasitesine değil yolun kırılma davranışına da büyük etki sağlamaktadır. Malzemelerin kalıcı deformasyonu olan plastik bölgede geosentetik donatının etki etmesi yol yapısının uzun süreli davranışında daha dayanıklı ve etkili davranmasını sağlaması beklenmektedir.

\section{Sonuçlar}

$\mathrm{Bu}$ çalışmada literatürde büyük bir soru işareti olarak gündemde olan ölçek etkisinin donatısız ve donatılı yol altı zeminindeki etkileri incelenmeye çalışılmıştır. Sonlu elemanlar programı kullanılarak yapılan analizler sonucunda elde edilen değerler karşılaştırılarak sonuçlar yorumlanmıştır. Donatısız modeller incelendiğinde numune boyutunun gerilmedeformasyon davranışına etkisi mühendislik açısından ihmal edilebilir düzeyde olurken, oturma miktarını ise orantılı olarak değiştirdiği belirlenmiştir. Fakat numune boyutu arasındaki fark örneğin yaklaşık 100 kata kadar çıktığında davranışın değiştiği ve yüklemenin başarı ile yapılamadığı yanal deformasyonlardan ötürü numunelerin daha düşük düşey yüklerde kırıldığ gözlenmiştir. Geosentetik ile güçlendirilmiş numunelerde ise donatı sayısının numunenin statik yüklenme sonrası davranışına etkisinin önemli derecede olabileceği belirlenmiştir. Donatı sayısı artıkça modellerdeki iyileştirme miktarı da artmaktadır. En fazla gerilme ve en az deformasyon donatı tabaka sayısı 3'e çıkarıldığında görülmüştür. Tek donatılı durumda ise donatının model yüzeyine daha yakın bir bölümü olan $\mathrm{H} / 4$ mesafesine konulması daha iyi sonuçlar vermiştir. Ayrıca, model boyutları arttıkça yanal basınç etkisinden kaynaklı olduğu düşünülen sebeplerden ötürü daha farklı davrandiğ 1 ve donatılı durumda model boyutlarının etkili olabileceği belirlenmiştir. Gerilme-deformasyon davranışında elastik bölgede benzer sonuçlar alınsa dahi plastik bölgede farkl1lıklar olmuştur. $\mathrm{Bu}$ durum bu çalışmanın, geosentetiğin oturma miktarı arttıkça daha iyi çalıştığını gösteren literatür çalışmaları ile uyumlu olduğunu göstermektedir. Ayrıca, donatı kırılma davranışına da etki etmiş farklı donatılar etkisinde farklı bölgelerde kırılma çizgilerinin oluştuğu gözlenmiştir. Böylece, 
donatılı yol numunesi testleri için boyut etkisinin özellikle plastik kısımda etkili olabileceği düşünülerek daha dikkatli olunmalıdır. Genellikle laboratuvar ve sonlu elemanlar benzer sonuçlar verse de bazı durumlarda farkliliklar görülebilmektedir. $\mathrm{Bu}$ nedenle yapılan bu araştırmanın sadece nümerik olarak yapıldığ 1 ve gelecekte deneysel çalışmalarla da incelenmesinin iyi olabileceği düşünülebilmektedir.

\section{Teşekkür}

$\mathrm{Bu}$ çalışmanın yürütülmesinde kullanılan sonlu elemanlar programının temini için Hacettepe Üniversitesi Bilimsel Araştırmalar Programına (FHD-2017-13555) teşekkür etmektedir.

\section{Kaynaklar}

[1] Saghebfar, M. (2014). Performance of Geotextilereinforced Bases for Paved Roads, PhD Dissertation, Kansas State University, Manhattan, KS.

[2] Zofka, A., Maliszewski, M., Maliszewska, D. (2017). Glass and carbon geogrid reinforcement of asphalt mixtures. Road Materials and Pavement Design, 18 (S1), 471-490.

[3] Latha, G.M. and Murthy, V.S. (2007). Effects of reinforcement form on the behavior of geosynthetic reinforced sand. Geotextiles and Geomembranes, 25 , 23-32.

[4] Nguyen, M., Blanc, J., Kerzrého, J. and Hornych, P. (2013). Review of glass fibre grid use for pavement reinforcement and APT experiments at IFSTTAR. Road Materials and Pavement Design, 14, S1, 287308.

[5] Elton, D. J., and Patawaran, M. A. B. (2004). Mechanically stabilized earth reinforcement tensile strength from tests of geotextile-reinforced soil. Transportation Research Record 1868, Transportation Research Board, Washington, DC, 81-88.

[6] Watts, G.R.A., Blackman, D.I., Jenner, C.G. (2004). The performance of reinforced unpaved sub-bases subjected to trafficking. Third European Geosynthetics Conference, vol. 1. Munich, 261-266

[7] Hufenus, R., Rueegger, R., Banjac, R., Mayorc, P., Springman, S.M., Brönnimann, R. (2006). Full-scale field tests on geosynthetic reinforced unpaved roads on soft subgrade, Geotextiles and Geomembranes, $\mathbf{2 4}$, 21-37.

[8] Cerato, A.B. and Lutenegger, A.J.(2007) Scale Effects of Shallow Foundation Bearing Capacity on Granular
Material. Journal of Geotechnical and Geoenvironmental Engineering, 133 (10): 11921202.

[9] Zhu, F., Clark, J.I. and Phillips, R.(2001) Scale Effect of Strip and Circular Footings Resting on Dense Sand. Journal of Geotechnical and Geoenvironmental Engineering, 127(7): 613-621.

[10] Gu, F., Luo, X., Luo, R., Lytton, R. L., Hajj, E. Y., \& Siddharthan, R. V. (2016) Numerical modeling of geogrid-reinforced flexible pavement and corresponding validation using large-scale tank test. Construction and Building Materials, 122, 214-230.

[11] Ramos-García, J.A., Castro, M. (2017). Linear viscoelastic behavior of asphalt pavements: 3D-FE response models. Construction and Building Materials, 136, 414-425.

[12] Djellali, A., Houam, A., Saghafi, B., Hamdane, A., Benghazi, Z. (2017). Static Analysis of Flexible Pavements over Expansive Soils. International Journal of Civil Engineering, 15, 391-400.

[13] Ahirwar, S.K. and Mandal, J.N. (2017). Finite Element Analysis of Flexible Pavement with Geogrids. Procedia Engineering, 189, 411-416.

[14] Zhang, J., Zhu, C., Li, X., Pei, J., Chen, J. (2017). Characterizing the three-stage rutting behavior of asphalt pavement with semi-rigid base by using UMAT in ABAQUS, Construction and Building Materials, 140, 496-507.

[15] Helwany, S., Dyer, J., Leidy, J. (1998). Finite-element analyses of flexible pavements. Journal of Transportation Engineering, 124, 5,: 491-499.

[16] Abu-Farsakh, M., Gub, J., Voyiadjis, G.Z. and Chen, Q. (2014). Mechanistic-empirical analysis of the results of finite element analysis on flexible pavement with geogrid base reinforcement, International Journal of Pavement Engineering, 15, 9, 786-798.

[17] Gray, D. H., and Al-Refeai, T. (1986). Behavior of fabric-versus fiber-reinforced sand. Journal of Geotechnical Engineering, 112, 8, 804-820. doi:10.1061/(ASCE)0733-9410/(ASCE)07339410(1986)112:8 (804).

[18] Ling, H.I. and Liu, H. (2003). Finite Element Studies of Asphalt Concrete Pavement Reinforced with Geogrid. Journal of Englneering Mechanics, 129, 7, 801-811.

[19] Wu, J. T., Pham, T. Q. \& Adams, M. T. (2013). Composite Behavior of Geosynthetic Reinforced Soil Mass (No. FHWA-HRT-10-077), FHWA, Richmond, VA, USA. 
[20] Kandolkar, S. S., Mandal, J. N. (2014). Effect of reinforcement on stress-strain behavior of stone dust, International Journal of Geotechnical Engineering, 8, 4, 383-395.

[21] Wu, H., Huang, B., Shu, X., Zhao, S. (2015). Evaluation of geogrid reinforcement effects on unbound granular pavement base courses using loaded wheel tester, Geotextiles and Geomembranes, 43, 462-469.

[22] Maher M., \& Gray D. H. (1990). Static Response of Sands Reinforced with Randomly Distributed Fibers, Journal of Geotechnical Engineering, 116, 11, 16611677. doi:10.1061/(ASCE) 0733-9410(1990)116: 11(1661).

[23] Chen, Q. (2007). An experimental study on characteristics and behavior of reinforced soil foundation, $P h D$ dissertation, Louisiana State University, Baton Rouge, USA.
[24] Sun, X., Han, J., Fei, J., Guo, J., Zhang, W. (2020) Geosynthetic-stabilized flexible pavements: Solution derivation and mechanistic-empirical analysis, Geotextiles and Geomembranes, 48, 4, 468-478.

[25] Imjai, T., Pilakoutas, K., Guadagnini, M. (2019) Performance of geosynthetic-reinforced flexible pavements in full-scale field trials, Geotextiles and Geomembranes, 47, 2, 217-229.

[26] Al-Hedad, A. Hadi, M.N.S. (2019) Road Materials and Pavement Design, Effect of geogrid reinforcement on the flexural behaviour of concrete pavements, Road Materials and Pavement Design, 20, 5, 1005-1025. 